\title{
Alterações de atributos químicos e físicos de um Latossolo Vermelho na sucessão milheto-soja
}

\section{Changes of Chemical and physical attributes of a Red Latosol in the millet-soybean succession}

\author{
Arlindo José da Costa RABELO'; Jeander Oliveira CAETANO²; Sihélio Júlio Silva CRUZ³ \\ ${ }^{1}$ Autor para correspondência, Mestrando em Produção Vegetal; Universidade de Rio Verde - UniRV, Faculdade de \\ Agronomia, Fazenda Fontes do Saber, Rio Verde - GO. CEP 75901-970; arlindo rabelo@outlook.com \\ ${ }^{2}$ Doutor em Agronomia; Universidade de Rio Verde - UniRV, Faculdade de Agronomia; jeandercaetano@gmail.com \\ ${ }^{3}$ Doutor em Agronomia; Instituto Federal Goiano - Campus Iporá; sihelio.cruz@ifgoiano.edu.br
}

Recebido em: 20-07-2017; Aceito em: 05-02-2019

\begin{abstract}
Resumo
No Cerrado, o milheto destaca-se como planta de cobertura, por desenvolver-se bem em condições adversas de clima e solo. Assim, avaliou-se o efeito de cultivo em sucessão milheto-soja nos atributos químicos do solo (pH, matéria orgânica, concentração de $\mathrm{Ca}, \mathrm{Mg}, \mathrm{K}$ e Al trocáveis, $(\mathrm{H}+\mathrm{Al})$ e teores de $\mathrm{P}$ disponíveis, nas profundidades de 0 a 0,20 m e 0,20 a 0,40 m), físicos do solo (resistência do solo à penetração de raízes, densidade e porosidade total do solo, nas profundidades de 0 a $0,10 \mathrm{~m}$ e 0,10 a 0,20 m), na produção e acúmulo de macronutrientes da biomassa seca da parte aérea de milheto e na produtividade da soja. O experimento foi instalado em um LATOSSOLO VERMELHO distrófico de textura argilosa, em Rio Verde-GO, safra 2013/2014. Os tratamentos foram compostos pelas variedades de milheto ADR500 e ADR300, pelos híbridos de milheto ADR7020 e ADR8010 e um tratamento-controle mantido sob vegetação espontânea. Utilizou-se o delineamento em blocos ao acaso, com quatro repetições. Os milhetos ADR500 e o ADR8010 apresentaram maior produção de biomassa seca da parte aérea. Os tratamentos sob cultivo de milheto elevaram o teor de potássio no solo, na profundidade de 0 a 0,20 m. As áreas com milheto apresentaram redução da resistência do solo à penetração e à densidade do solo, em relação à área com vegetação espontânea. Embora os milhetos testados melhorem algumas das condições químicas e físicas do solo, isso não se refletiu nos rendimentos da soja como cultura sucessora.
\end{abstract}

Palavras-chave adicionais:; biomassa seca; nutrientes; Pennisetum glaucum; resistência do solo à penetração.

\begin{abstract}
In the Cerrado, millet stands out as a cover plant, because it develops well under adverse weather and soil conditions. Thus, the effect of millet-soybean succession cultivation on soil chemical attributes $(\mathrm{pH}$, organic matter, exchangeable $\mathrm{Ca}, \mathrm{Mg}, \mathrm{K}$ and $\mathrm{Al}$ contents, $(\mathrm{H}+\mathrm{Al})$ and available $\mathrm{P}$ contents, at depths of $0-0,20 \mathrm{~m}$ and $0,20-0,40 \mathrm{~m}$ ) soil physical ones (soil resistance to root penetration, total soil density and porosity at depths of $0-0,10 \mathrm{~m}$ and $0,10-0,20 \mathrm{~m}$ ), in the production and accumulation of macronutrients of the dry biomass of millet shoot and soybean yield was assessed. The experiment was carried out in a clayey dystrophic Red Latosol in Rio Verde, GO, crop 2013/2014. The treatments were composed by the ADR500 and ADR300 millet varieties, the ADR7020 and ADR8010 millet hybrids and a control treatment kept under spontaneous vegetation. A randomized block design with four replications was used. The ADR500 and the ADR8010 millet showed higher dry shoot biomass production. The treatments under millet cultivation increased the soil potassium content in the depth of $0-0,20 \mathrm{~m}$. The millet areas presented reduced soil resistance to soil penetration and density in relation to the area with spontaneous vegetation. Although tested millets improve some of the chemical and physical conditions of the soil due to water stress, that did not reflect on the soybean yields as successor crop.
\end{abstract}

Additional keywords: dry biomass; nutrients; Pennisetumglaucum; soil resistance to penetration.

\section{Introdução}

A região Centro-Oeste destaca-se como maior produtora de grãos do Brasil (CONAB, 2015), isso devido à pesquisa e ao emprego de práticas conservacionistas, como o sistema de semeadura direta
(SSD) aliado ao cultivo de plantas de cobertura do solo. O uso dessas coberturas vegetais proporcionaram o aumento de produtividade, a sustentabilidade na produção agrícola e a preservação dos recursos naturais do Cerrado (Cardoso et al., 2013).

Em relação ao cultivo dessas plantas de 
cobertura em sucessão com a soja, são evidentes a manutenção e a melhoria dos atributos físicos e químicos do solo, em virtude de as plantas de cobertura apresentarem um sistema radicular vigoroso e alta produção de biomassa seca, a qual, com o tempo, torna-se palhada para a cobertura do solo e passa a protegê-lo. Além disso, essa palhada atenua os efeitos da compactação do solo, proporcionando o aumento nos teores de matéria orgânica do solo, melhorando a sua estrutura e também a ciclagem de nutrientes, podendo conferir melhores condições para o bom desenvolvimento da cultura sucessora (Boer, 2006; Carvalho \& Amabile, 2006; Carvalho et al., 2007).

Entretanto, no Cerrado brasileiro, há dificuldade na escolha de plantas para formação de biomassa e cobertura vegetal do solo, já que geralmente o período de semeadura dessas plantas é após o cultivo da soja, na entressafra, época em que ocorre déficit hídrico, podendo dificultar o estabelecimento dessas culturas (Teixeira et al., 2005; Embrapa, 2011). Dessa forma, é importante escolher plantas de cobertura com características de rusticidade e adaptabilidade às condições edafoclimáticas da região para o seu desenvolvimento e produção de biomassa vegetal suficiente para a proteção do solo (Alvarenga et al., 2001; Torres et al., 2014).

Nesse sentido, o milheto destaca-se por apresentar essas características e por desenvolver-se de forma rápida, sendo uma boa opção como planta de cobertura de entressafra, no cultivo em sucessão com a soja, na região do Cerrado (Pires et al. 2007). Ainda se ressalta que esse cereal proporciona alta produção de biomassa seca e apresenta um sistema radicular profundo e vigoroso, capaz de romper camadas compactadas, promovendo, então, a formação de bioporos e o aumento da areação do solo (Guimarães et al., 2013; Burle et al., 2006). Por isso, o cultivo de milheto tem promovido a ciclagem de nutrientes e a restruturação do solo e, consequentemente, a redução dos custos operacionais e com insumos agrícolas (Cardoso et al., 2013; Pires et al., 2007).

Assim, objetivou-se avaliar os efeitos do cultivo da sucessão milheto-soja na produção e no acúmulo de macronutrientes na parte aérea da biomassa seca de diferentes materiais de milheto, seus efeitos em alguns atributos químicos e físicos do solo e na produtividade da soja.

\section{Material e métodos}

O estudo foi conduzido na safra de 2013/2014, em área experimental no município de Rio Verde - GO (17047'30" S e $50^{\circ} 57^{\prime} 44^{\prime \prime} \mathrm{W}$, com altitude de $765 \mathrm{~m}$ ), em um LATOSSOLO VERMELHO distrófico, textura argilosa (Embrapa, 2006). Nessa área, antes desse período, era comum o cultivo da soja em sistema semeadura direta, há mais de seis anos. O clima da região, conforme classificação de Köppen, é do tipo Aw (tropical chuvoso), com temperatura média de $22,1 \stackrel{\circ}{ } \mathrm{C}$ e precipitação pluviométrica de $1.776 \mathrm{~mm}$ por ano, sendo que os dados climáticos durante a condução do experimento estão apresentados na Figura 1.

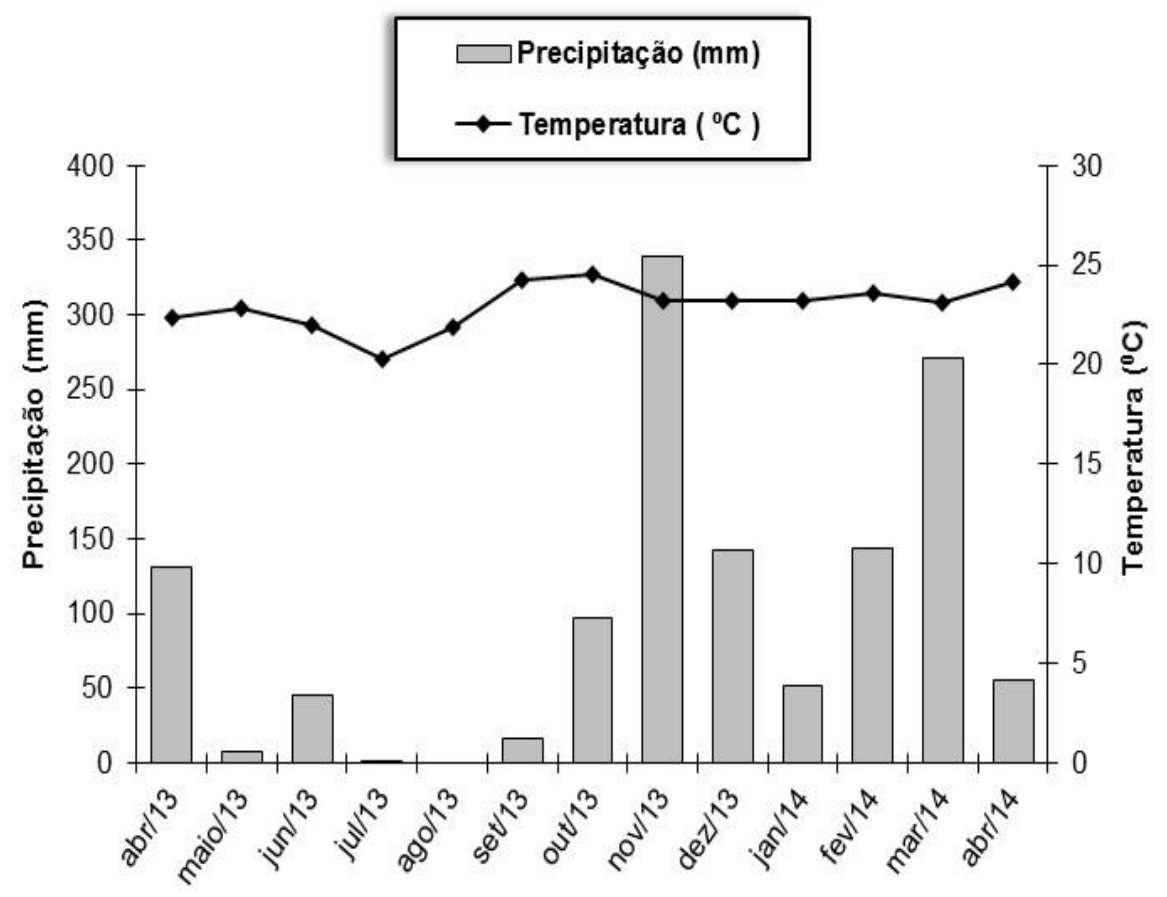

Figura 1 - Variação mensal da temperatura média do ar e precipitação pluvial entre abril de 2013 e abril de 2014 , Rio Verde - GO. Monthly variation of average air temperature and rainfall between April 2013 and April 2014, Rio Verde-GO. 
Tabela 1 - Caracterização química e física do solo da área experimental, nas profundidades de 0 a 0,20 m e de 0,20 a $0,40 \mathrm{~m}$, antes da instalação do experimento (Rio Verde - GO, 2012). Chemical and physical characterization of the soil of the experimental area at depths of 0 to $0,20 \mathrm{~m}$ and 0,20 to $0,40 \mathrm{~m}$, before the experiment (Rio Verde-GO, 2012).

\begin{tabular}{|c|c|c|c|c|c|c|c|c|c|c|}
\hline \multirow{2}{*}{$\begin{array}{l}\text { Profundidade } \\
\text { (m) }\end{array}$} & \multirow{2}{*}{$\begin{array}{c}\mathrm{pH} \\
\mathrm{CaCl}_{2}\end{array}$} & \multirow{2}{*}{$\begin{array}{c}\mathrm{P}^{1} \\
\left(\mathrm{mg} \mathrm{dm}^{-3}\right)\end{array}$} & $\mathrm{K}$ & $\mathrm{H}+\mathrm{Al}$ & $\mathrm{Ca}$ & $\mathrm{Mg}$ & $\mathrm{Al}$ & CTC & $\mathrm{m}$ & V \\
\hline & & & ---- & - & \multicolumn{2}{|c|}{$\left(\mathrm{cmol}_{\mathrm{c}} \mathrm{dm}^{-3}\right)$} & - & ------ & \multicolumn{2}{|c|}{----- (\%) ----- } \\
\hline $0-0,20$ & 5,33 & 2,90 & 0,27 & 5,18 & 2,08 & 0,65 & 0,10 & 8,18 & 3,23 & 36,39 \\
\hline \multirow[t]{3}{*}{$0,20-0,40$} & 5,32 & 1,36 & 0,24 & 4,30 & 1,69 & 0,54 & 0,08 & 6,77 & 3,14 & 36,48 \\
\hline & $\begin{array}{l}\text { Matéria } \\
\text { orgânica }\end{array}$ & Argila & Silte & Areia & - & - & - & - & - & - \\
\hline & ------ & - $\left(\mathrm{g} \mathrm{kg}^{-1}\right.$ & ------. & ------ & - & - & - & - & - & - \\
\hline $0-0,20$ & 16,40 & 500 & 150 & 350 & - & - & - & - & - & - \\
\hline $0,20-0,40$ & 15,79 & 510 & 140 & 350 & - & - & - & - & - & - \\
\hline
\end{tabular}

${ }^{1}$ Extração de fósforo pelo método Mehlich 1

As amostras, para caracterização química e física do solo, foram coletadas antes da instalação do experimento (Embrapa, 1997; Embrapa, 1999).

$O$ experimento foi conduzido em delineamento de blocos casualizados, constituído de cinco tratamentos, com quatro repetições, totalizando vinte unidades experimentais. Cada parcela foi composta por 5 $\mathrm{m}$ de comprimento e $5 \mathrm{~m}$ de largura, totalizando $25 \mathrm{~m}^{2}$ de área total. Os tratamentos foram as variedades de milheto ADR500 e ADR300 e os híbridos ADR7020 e ADR8010, e um tratamento-controle mantido sob pousio com vegetação espontânea.

Antes da semeadura dos milhetos, realizou-se a abertura mecânica dos sulcos de semeadura com espaçamento de $0,5 \mathrm{~m}$ entre as linhas, para isso utilizou-se de uma semeadora-adubadora. A semeadura do milheto foi realizada em 06-05-2013, 60 dias após a colheita da soja, sendo que as sementes de milheto foram semeadas manualmente. Além disso, objetivando a manutenção de 250 mil plantas ha ${ }^{-1}$, foi realizado, aos 20 dias após a emergência da cultura, o desbaste das plantas de milheto excedentes. Não foi realizada a adubação de semeadura e cobertura, pois objetivou-se avaliar o desenvolvimento das plantas de milheto apenas com o residual da cultura da soja, avaliando-se a eficiência da ciclagem de cada cobertura, mesmo sob condições de baixa fertilidade. As parcelas com o tratamento controle permaneceram em pousio sem dessecação (vegetação espontânea).

A avaliação da produção da biomassa seca dos materiais de milheto foi realizada 70 dias após a emergência das plantas. Essas plantas foram coletadas em área amostral de $1,50 \mathrm{~m}^{2}$ de cada parcela, fazendo o corte, rente ao solo, da parte aérea do milheto (folhas, colmo e inflorescência). Em seguida, os materiais vegetais amostrados foram submetidos à secagem em estufa de circulação forçada de ar, a $65^{\circ} \mathrm{C}$, até peso constante, para a determinação da biomassa seca da parte aérea do milheto. A determinação dos teores de macronutrientes $\mathrm{N}, \mathrm{P}, \mathrm{K}, \mathrm{Ca}, \mathrm{Mg}$ e S foi realizada de acordo com a metodologia descrita por Malavolta et al. (1997). O acúmulo de macronutrientes na parte aérea das plantas de milheto foi calcu- lado utilizando-se da produção da biomassa seca da parte aérea das plantas de milheto e do teor desses nutrientes da biomassa seca.

Antes da semeadura da soja, no dia 28-102013, foram realizadas coletas de amostras deformadas de solo, nas camadas de 0 a 0,20 m e 0,20 a 0,40 $\mathrm{m}$ de profundidade. Utilizou-se de um trado holandês, fazendo a coleta nas entrelinhas do milheto. Para compor a amostra composta do solo, coletaram-se 10 subamostras na diagonal de cada parcela. A determinação da acidez ativa ( $\mathrm{pH}$ em $\mathrm{CaCl}_{2}$ ); concentração de matéria orgânica do solo; teores de $\mathrm{Ca}, \mathrm{Mg} \mathrm{K}$ e Al trocáveis; acidez potencial $(\mathrm{H}+\mathrm{Al})$, e teor disponível de $P$ foi realizada de acordo com a Embrapa (1999).

A vegetação (milheto e vegetação expontânea) foi dessecada mediante a aplicação de herbicida glyphosate (glifosato-sal de isopropilamina $480 \mathrm{~g} \mathrm{~L}^{-1}$ ), em 04-11-2013. Em 13-11-2013, foi realizada a semeadura da cultivar de soja NS7490RR sob a palhada de milheto, sendo utilizado o espaçamento de $0,50 \mathrm{~m}$ nas entrelinhas, visando a atingir uma população final de 280 mil plantas ha ${ }^{-1}$. Antes da semeadura, as sementes de soja foram inoculadas com Bradyrhizobium japonicum. A adubação de semeadura constituiu-se de $400 \mathrm{~kg} \mathrm{ha}^{-1}$ da fórmula 2-20-18.

Entre os dias 20 e 21 de dezembro de 2013, foram coletadas as amostras de solo, na área central de cada parcela, para a análise dos atributos físicos do solo: densidade de partículas do solo, densidade do solo, umidade gravimétrica e determinação da resistência do solo à penetração.

Para a determinação da porosidade total do solo, foram realizadas amostragens de solo para análise da densidade de partículas (Dp), pelo método do balão volumétrico (Embrapa, 1997). Assim, foram coletadas duas amostras de solo por parcela, na profundidade de 0 a 0,20 m, utilizando um trado holandês. Após a determinação da Dp, calculou-se a média geral.

A densidade do solo (Ds) e o teor de umidade gravimétrica $(\mathrm{Ug})$ foram determinados pelo método do anel volumétrico (Embrapa, 1997), utilizando amostras com estrutura indeformadas, retiradas com anel de 
aço de bordas cortantes com volume interno de 269 $\mathrm{cm}^{3}$. Para cada profundidade estudada (0 a $0,10 \mathrm{~m}$ e 0,10 a $0,20 \mathrm{~m}$ ), foram retiradas duas subamostras por parcela. A resistência do solo à penetração $(R P)$ foi determinada na área útil de cada parcela com o auxílio de um penetrômetro de impacto, modelo proposto por Stolf (1991), realizando dez repetições por parcela, sendo 5 na linha e 5 na entrelinha, até à profundidade de $40 \mathrm{~cm}$. Sendo que, no momento da penetração, o solo se encontrava com teor médio de $\mathrm{Ug}=22 \%$.

Para a avaliação da produtividade da soja e da massa de cem grãos, as plantas foram colhidas manualmente em área útil de $8 \mathrm{~m}^{2}$ por parcela. Os valores da massa seca de grãos foram corrigidos para $13 \%$ de umidade. Após a quantificação dos dados avaliados, foi realizada a análise de variância, sendo que, quando o $\mathrm{F}$ foi significativo, aplicou-se o teste de Tukey, a $5 \%$ de probabilidade.

\section{Resultados e discussão}

Nas condições em que os milhetos foram cultivados, a variedade ADR500 e o híbrido ADR8010 produziram maior quantidade de biomassa seca (BMS) da parte aérea em relação aos demais (Tabela 2). Segundo Pereira Filho et al. (2003), esses resultados demonstraram que os mesmos apresentaram características distintas dos demais materiais em relação à produção de biomassa.

Tabela 2 - Produção de biomassa seca (BMS) e quantidade acumulada de (N, $\mathrm{P}, \mathrm{Ca}, \mathrm{Mg}$ e $\mathrm{S}$ ) na parte aérea de plantas de milheto. Production of dry biomass (BMS) and accumulated amount of (N, $P, C a, M g$ and $S$ ) in the aerial part of millet plants.

\begin{tabular}{|c|c|c|c|c|c|c|c|}
\hline \multirow{2}{*}{ Tratamentos } & \multirow{2}{*}{$\begin{array}{c}\text { BMS } \\
\left(\mathrm{kg} \mathrm{ha}^{-1}\right)\end{array}$} & $\mathrm{N}$ & $P$ & $\mathrm{~K}$ & $\mathrm{Ca}$ & $\mathrm{Mg}$ & S \\
\hline & & \multicolumn{6}{|c|}{ - Quantidade acumulada $\left(\mathrm{kg} \mathrm{ha}^{-1}\right)$} \\
\hline ADR500 & 1950 a & $36,5 \mathrm{a}$ & $1,7 \mathrm{a}$ & $44,3 \mathrm{a}$ & $9,8 \mathrm{a}$ & $4,9 \mathrm{a}$ & $1,4 \mathrm{a}$ \\
\hline ADR300 & $1532 b$ & $22,2 \mathrm{~b}$ & $0,7 \mathrm{~b}$ & $30,0 \mathrm{~b}$ & $7,5 a b$ & $3,5 a$ & $0,9 b$ \\
\hline ADR7020 & 1447 b & 24,8 b & $0,9 a b$ & $33,8 a b$ & $6,6 \mathrm{~b}$ & 3,3 a & $1,2 a b$ \\
\hline ADR8010 & $1972 \mathrm{a}$ & $34,1 \mathrm{a}$ & $1,2 \mathrm{ab}$ & $43,1 \mathrm{a}$ & $9,1 \mathrm{ab}$ & $4,7 \mathrm{a}$ & $1,5 \mathrm{a}$ \\
\hline CV $(\%)$ & 10,4 & 11,4 & 34,6 & 14,9 & 15,4 & 19,2 & 19,5 \\
\hline
\end{tabular}

Médias seguidas de mesma letra minúscula na coluna não diferem entre si, pelo teste de Tukey a $5 \%$ de probabilidade.

Averages followed by the same lowercase letter in the column do not differ from each other, based on the Tukey test at $5 \%$ probability.

A produção média de BMS dos diferentes materiais de milheto aqui testados ficou abaixo de $5.000 \mathrm{~kg} \mathrm{ha}^{-1}$ (Tabela 2), sendo o mínimo citado por Menezes et al. (2009) para a obtenção de boa taxa de cobertura e maior permanência da palhada na superfície do solo. Essa baixa produção de BMS ocorreu devido às condições de baixo índice de precipitação durante a época da condução do experimento, na entressafra (Figura 1) e, também, devido à não realização da adubação para a cultura do milheto. Em consequência dessa ausência de adubação, possivelmente, o baixo teor de fósforo no solo, associado ao déficit hídrico estiveram responsáveis como limitante ao desenvolvimento da cultura, já que os teores de $\mathrm{Ca}$, $\mathrm{Mg}$ e $\mathrm{K}$ se encontravam em níveis adequados, segundo Sousa \& Lobato (2004), antes da implantação do experimento (Tabela 1).

Trabalhos conduzidos com milheto, também fora da época adequada de cultivo, obtiveram baixa produção de BMS, como observado por Marcante et al. (2011), Torres et al. (2008) e Teixeira et al. (2010), que obtiveram, respectivamente, 2.300, 3.600 e $2.364 \mathrm{~kg} \mathrm{ha}^{-1}$. Segundo estes autores, as condições climáticas desfavoráveis ocorridas na época da condução do experimento foram responsáveis pela baixa produção de BMS. Para Carvalho et al. (2013), que obtiveram produção média de $968 \mathrm{~kg} \mathrm{ha}^{-1}$ de BMS, a baixa produção de BMS é atribuída não só ao estresse hídrico, mas também à ausência de adubação em áreas com deficiência em algum nutriente.

O milheto ADR500 e o ADR8010 não diferiram entre si e proporcionaram maior acúmulo de $\mathrm{N}$ em relação ao ADR300 e ao ADR7020 (Tabela 2). O maior acúmulo de $\mathrm{N}$ na BMS do ADR500 e do ADR8010 ocorreu possivelmente devido à maior produção de BMS dos mesmos (Tabela 2).

Devido à baixa produção de BMS, a quantidade de $\mathrm{N}$ acumulado foi relativamente baixa, se comparado aos valores encontrados por Torres et al. (2005), que obtiveram $55,8 \mathrm{~kg} \mathrm{ha}^{-1}$ de $\mathrm{N}$ com produção de $3.600 \mathrm{~kg} \mathrm{ha}^{-1}$ de BMS, com a semeadura realizada no mês de março, na região do Cerrado. Enquanto Teixeira et al. (2010) obtiveram 25,4 $\mathrm{kg} \mathrm{ha}^{-1}$ de N, com produtividade de $2.364 \mathrm{~kg} \mathrm{ha}^{-1}$ de BMS em época também desfavorável ao estabelecimento da cultura. Isso demonstra que a capacidade do milheto em produzir biomassa seca e acumular nutrientes depende das condições em que essa planta é cultivada.

O milheto ADR500 apresentou maior acúmulo de fósforo em relação ao ADR300, sendo que estes não diferiram dos demais milhetos (Tabela 2). O maior acúmulo de $\mathrm{P}$ do ADR500 demonstrou sua maior capacidade de extrair $P$ do solo em relação ao ADR300 nessas condições de cultivo. O baixo acúmulo de $P$ na biomassa dos milhetos foi devido ao 
baixo teor de fósforo e à baixa produção de BMS (Tabela 2). Em trabalho realizado por Teixeira et al. (2010), foi verificado o acúmulo de $3,81 \mathrm{~kg} \mathrm{ha}^{-1}$ de $P$, para uma produtividade de $2.364 \mathrm{~kg} \mathrm{ha}^{-1}$ de BMS.

Os milhetos ADR500 e o ADR8010 proporcionaram maior acúmulo de potássio em relação ao ADR300, sendo que estes não diferiram do ADR7020 (Tabela 2). Essa maior quantidade acumulada de potássio é devido à maior produção de BMS observada no ADR8010 e no ADR500 (Tabela 2).

A quantidade acumulada de potássio pelas plantas de milheto foi, em média, $38 \mathrm{~kg} \mathrm{ha}^{-1}$, quantidade abaixo da encontrada por Teixeira et al. (2010), que foi de $47 \mathrm{~kg} \mathrm{ha}^{-1}$ de $\mathrm{K}$, com produção de $2.360 \mathrm{~kg} \mathrm{ha}^{-1}$ de BMS. Essa menor quantidade acumulada de $\mathrm{K}$ na $\mathrm{BMS}$, em relação à observada pelos autores, provavelmente, ocorreu devido ao cultivo de milheto do presente estudo ter sido realizado em condições desfavoráveis, tanto de umidade como de fertilidade do solo, o que prejudicou a produção de BMS.

$\mathrm{O}$ valor médio acumulado de $38 \mathrm{~kg} \mathrm{ha}^{-1}$ de $\mathrm{K}$ na BMS equivale a $45,8 \mathrm{~kg}$ de $\mathrm{K}_{2} \mathrm{O}$, quantidades suficientes para suprir a demanda de potássio para a produção de mais de 2.000 kg de grãos de soja, já que são absorvidos pelos grãos, em média, $20 \mathrm{~kg}$ de $\mathrm{K}_{2} \mathrm{O}$ para cada $1.000 \mathrm{~kg}$ de grãos produzidos (Embrapa, 2011). Isso demonstra que, mesmo sob condições de baixa umidade e fertilidade do solo, o milheto manteve sua capacidade de reciclagem de potássio.

A variedade de milheto ADR500 apresentou maior acúmulo de $\mathrm{Ca}$ em relação ao ADR7020, sendo que estes não diferiram dos demais materiais de milheto (Tabela 2). Esse maior acúmulo de $\mathrm{Ca}$ na BMS do ADR500, em relação ao ADR7020, ocorreu possivelmente devido à produção de BMS do ADR500 ter sido superior, podendo com isso acumular mais $\mathrm{Ca}$. Os valores acumulados de $\mathrm{Mg}$ na biomassa seca não apresentaram diferença significativa entre os materiais de milheto (Tabela 2). O ADR500 e o ADR8010 proporcionaram maior acúmulo de enxofre em relação ao ADR300, sendo que estes não diferiram do ADR7020 (Tabela 2). O maior acúmulo foi, possivelmente, devido à produção de BMS do ADR500 e ADR8010 ter sido superior à do ADR300.

A BMS dos diferentes materiais de milheto acumulou, em média, 8,26 kg ha-1 de $\mathrm{Ca}, 4,34 \mathrm{~kg} \mathrm{ha}^{-1}$ de $\mathrm{Mg}$ e 1,28 $\mathrm{kg} \mathrm{ha}^{-1}$ de S, portanto médias abaixo das verificadas por Torres et al. (2008), que foram de $23,17 \mathrm{~kg} \mathrm{ha}^{-1}$ de $\mathrm{Ca}, 11,22 \mathrm{~kg} \mathrm{ha}^{-1}$ de $\mathrm{Mg}$ e 6,52 $\mathrm{kg}^{-1}$ ${ }^{1}$ de $\mathrm{S}$, com produção média de $3.600 \mathrm{~kg} \mathrm{ha}^{-1}$ de BMS. Esse baixo acúmulo de $\mathrm{Ca}, \mathrm{Mg}$ e $\mathrm{S}$ é atribuído à baixa produção de BMS, em função da época de plantio.

Os tratamentos com diferentes materiais de milheto e a vegetação espontânea não proporcionaram diferença significativa quanto ao seu efeito nos teores de $\mathrm{Ca}$ e $\mathrm{Mg}$ no solo, nas profundidades de 00,20 e 0,20-0,40 m (Tabela 3). Mesmo os teores de $\mathrm{Ca}$ e $\mathrm{Mg}$ no solo se encontrarem em níveis adequados na camada de 0-0,20 m (Sousa \& Lobato, 2004), as plantas de milheto não extraíram esses elementos em quantidades suficientes para promover efeitos significativos entre os tratamentos, pois a época de cultivo estava com baixa umidade do solo, o que restringiu a absorção desses nutrientes pelas plantas.

O cultivo com os diferentes materiais de milheto proporcionou maior teor de $\mathrm{K}$ no solo em relação à vegetação espontânea, na profundidade de 00,20 m (Tabela 3). Isso é devido ao $\mathrm{K}$ ser liberado de forma mais rápida, por não fazer parte da estrutura orgânica vegetal (Meurer, 2006). Com isso, a taxa de liberação de $\mathrm{K}$ da BMS pode atingir de $75 \%$ a $87 \%$ entre 30 e 60 dias, respectivamente, proporcionando maior velocidade de reciclagem do nutriente em relação aos demais minerais (Boer et al., 2007). Na profundidade de 0,20 - 0,40 m, os maiores teores de $\mathrm{K}$ no solo foram observados nas áreas com o ADR500 e o ADR8010 em relação à vegetação espontânea, sendo que estes não diferiram dos demais (Tabela 3). Diante disso, o cultivo dos diferentes materiais de milheto demonstram sua capacidade de reciclagem de $\mathrm{K}$.

Nas áreas cultivadas com milheto, os teores de $\mathrm{K}^{+}$no solo, na profundidade de 0-0,20 m, ficaram acima do encontrado na Tabela 1 , sendo que, na área com vegetação espontânea, estes valores ficaram abaixo do verificado nessa tabela. De acordo com Sousa \& Lobato (2004), para a profundidade de 0 a $0,20 \mathrm{~m}$, os teores de $\mathrm{K}^{+}$no solo apresentaram níveis médios nas áreas sob milheto e baixo na área sob vegetação espontânea (Tabela 3). Isso demonstrou, novamente, o efeito do milheto na reciclagem de potássio.

Segundo Pereira Filho (2003), o milheto, por possuir um sistema radicular robusto e profundo, possibilita que o mesmo seja eficiente como planta recicladora de nutriente, capaz de extrair potássio das camadas mais profundas e disponibilizá-lo para as camadas mais superficiais, logo após a decomposição de sua biomassa seca das partes aérea e radicular.

Os tratamentos não diferiram significativamente quanto ao seu efeito na concentração de $P$ no solo, na profundidade de 0-0,20 m; enquanto, para 0,20-0,40 m, o tratamento com o ADR7020 apresentou maior teor de $P$ em relação aos milhetos ADR500 e ADR8010, sendo que os demais não diferiram dos mesmos, bem como da vegetação espontânea (Tabela 3). O menor teor de $\mathrm{P}$, na profundidade de 0 0,20 m, em áreas cultivadas com os milhetos ADR500 e ADR8010 em relação ao ADR7020, ocorreu, possivelmente, devido à maior extração deste nutriente proporcionada por esses milhetos, já que eles produziram maior quantidade de biomassa seca em relação ao ADR7020, aumentando com isso a quantidade extraída de $\mathrm{P}$ (Tabela 2). $\mathrm{O}$ teor médio de $\mathrm{P}$ para a profundidade de $0-0,20 \mathrm{~m}$, em todos os tratamentos, foi classificado como muito baixo (Sousa \& Lobato, 2004), ocasionado pelos baixos teores iniciais do solo e, também, pela não realização da adubação com $\mathrm{P}$. 
Tabela 3 - Médias de teores de $\mathrm{Ca}^{2+}, \mathrm{K}^{+}$, e $\mathrm{Mg}^{2+}$ tocáveis, $\mathrm{P}$ disponível e matéria orgânica do solo (MOS), de um LATOSSOLO VERMELHO distrófico sob diferentes materiais de milheto e sob vegetação espontânea, antes da semeadura de soja, da safra de 2013/2014. Averages of exchangeable $\mathrm{Ca}^{2+}, \mathrm{K}^{+}, \mathrm{Mg}^{2+}$ contents, available $P$ and soil organic matter (MOS) of a dystrophic Red Latosol under different millet materials and under spontaneous vegetation, prior to the sowing of soybeans of the 2013/2014crop.

\begin{tabular}{|c|c|c|c|c|c|c|}
\hline \multirow{2}{*}{$\begin{array}{l}\text { Profundidade } \\
\text { (m) }\end{array}$} & \multicolumn{5}{|c|}{ Tratamentos } & \multirow[b]{2}{*}{ CV (\%) } \\
\hline & ADR500 & ADR300 & ADR7020 & ADR8010 & $\begin{array}{c}\text { Vegetação } \\
\text { Espontânea }\end{array}$ & \\
\hline \multirow{3}{*}{$\begin{array}{l}0-0,20 \\
0,20-0,40\end{array}$} & & & $\mathrm{a}^{2+},\left(\mathrm{cmol}_{\mathrm{c}} \mathrm{d}\right.$ & & & \\
\hline & $1,75 \mathrm{a}$ & $1,84 \mathrm{a}$ & 1,79 a & $2,03 a$ & $1,99 a$ & 8,3 \\
\hline & $1,41 \mathrm{a}$ & $1,52 \mathrm{a}$ & $1,58 \mathrm{a}$ & $1,60 \mathrm{a}$ & $1,56 \mathrm{a}$ & 9,7 \\
\hline \multirow{3}{*}{$\begin{array}{l}0-0,20 \\
0,20-0,40\end{array}$} & & tis &,$+{ }^{+} \mathrm{cmol}_{\mathrm{c}} \mathrm{dm}$ & & & \\
\hline & $0,32 \mathrm{a}$ & $0,30 a$ & $0,30 \mathrm{a}$ & $0,31 \mathrm{a}$ & $0,21 \mathrm{~b}$ & 10,8 \\
\hline & $0,25 \mathrm{a}$ & $0,20 a b$ & $0,21 a b$ & $0,23 a$ & $0,16 \mathrm{~b}$ & 10,7 \\
\hline \multirow{3}{*}{$\begin{array}{l}0-0,20 \\
0,20-0,40\end{array}$} & & & $\mathrm{~g}^{2+},\left(\mathrm{cmol}_{\mathrm{c}} \mathrm{C}\right.$ & & & \\
\hline & $0,48 a$ & $0,49 a$ & $0,55 \mathrm{a}$ & $0,54 a$ & $0,61 \mathrm{a}$ & 11,5 \\
\hline & $0,37 \mathrm{a}$ & $0,44 \mathrm{a}$ & $0,49 a$ & $0,45 \mathrm{a}$ & $0,46 \mathrm{a}$ & 11,7 \\
\hline \multirow{3}{*}{$\begin{array}{l}0-0,20 \\
0,20-0,40\end{array}$} & & & Uehlich), (m & & & \\
\hline & $2,25 \mathrm{a}$ & $2,71 \mathrm{a}$ & $2,59 \mathrm{a}$ & $2,25 \mathrm{a}$ & 2,79 a & 8,0 \\
\hline & $1,07 \mathrm{~b}$ & $1,20 a b$ & $1,39 \mathrm{a}$ & $1,03 \mathrm{~b}$ & $1,28 \mathrm{ab}$ & 12,3 \\
\hline \multirow{3}{*}{$\begin{array}{l}0-0,20 \\
0,20-0,40\end{array}$} & & & MOS, $(\mathrm{g} \mathrm{dr}$ & & & \\
\hline & $21,23 \mathrm{a}$ & $20,18 a$ & $18,44 a b$ & $21,50 \mathrm{a}$ & $15,88 \mathrm{~b}$ & 9,5 \\
\hline & $18,62 \mathrm{a}$ & $17,00 \mathrm{a}$ & $17,56 \mathrm{a}$ & $19,13 \mathrm{a}$ & $15,24 \mathrm{a}$ & 13,0 \\
\hline
\end{tabular}

Médias seguidas de mesma letra minúscula na linha não diferem entre si, pelo teste de Tukey, a $5 \%$ de probabilidade. Averages followed by the same lowercase letter in the line do not differ from each other, based on the Tukey test, at $5 \%$ probability.

Os materiais dos milhetos ADR500, ADR300 e ADR8010 proporcionaram maior teor de matéria orgânica do solo (MOS) em relação à vegetação espontânea, na profundidade de 0-0,20 m, sendo que o ADR7020 não apresentou diferença dos mesmos, bem como da vegetação espontânea (Tabela 3). Os teores de MOS apresentaram níveis considerados baixos na profundidade de $0-0,20 \mathrm{~m}$ (Sousa \& Lobato, 2004). Em relação aos teores de MOS, na profundidade de 0,20-0,40 m, não se observou diferença significativa. Os efeitos da decomposição de palhada para a maior adição de MOS dependem de maior espaço de tempo.

A biomassa seca de milheto, tanto sua parte aérea quanto a radicular, tem a capacidade de fornecer carbono ao solo que, após sua mineralização, proporciona o aumento dos teores de MOS, contribuindo assim com a reciclagem de nutrientes (Penteado, 2010). Além disso, essa MOS também contribui para a melhoria da permeabilidade e da retenção de água pelo solo (Maurer, 2007).

O cultivo de plantas de milheto não influenciaram no $\mathrm{pH}\left(\mathrm{CaCl}_{2}\right)$, acidez potencial $(\mathrm{H}+\mathrm{Al})$, na saturação por bases $(\mathrm{V} \%)$ e por alumínio $(\mathrm{m} \%)$ do solo, nas profundidades de 0-0,20 e 0,20-0,40 m (Tabela 4). De acordo com as médias observadas a $\mathrm{m} \%$ encontra-se em níveis baixos, e o $\mathrm{pH} \mathrm{CaCl}$, em níveis adequados, na camada de 0-0,20 m (Sousa \& Lobato, 2004). Isso, possivelmente, devido ao solo da área já ter apresentado anteriormente esses níveis baixos para $\mathrm{m} \%$ e adequados para $\mathrm{pH}$ (Tabela 1 ).
No solo cultivado com ADR7020, ocorreu o menor teor de $\mathrm{Al}^{3+}$ em relação aos tratamentos com ADR500 e ADR300, na profundidade de $0-0,20 \mathrm{~m}$, sendo que os demais não diferiram dos mesmos. Apesar disso, os teores de $\mathrm{Al}^{3+}$ trocáveis, em ambos os tratamentos, na camada de $0-0,20 \mathrm{~m}$, foram considerados médios, não prejudicando o desenvolvimento da soja (Embrapa, 2011). Na camada de 0,20-0,40 m, não se observou diferença significativa entre os tratamentos em relação ao teor de $\mathrm{Al}^{3+}$ trocável.

O tratamento com ADR8010 proporcionou maior CTC no solo em relação ao ADR7020, sendo que os demais não diferiram dos mesmos (Tabela 4). Talvez essa diferença seja, possivelmente, em virtude de a capacidade do ADR8010 extrair os nutrientes em profundidade e de o mesmo ter produzido maior quantidade de biomassa em relação ao ADR7020 (Tabela 2). Essa quantidade maior de biomassa significa maior teor de nutrientes e de matéria orgânica, que ocasionaram a elevação da CTC do solo.

O cultivo com os milhetos ADR300, ADR500, ADR7020 e ADR8010 proporcionou a redução da RP, Ds e elevação da Pt em relação à área sob vegetação espontânea (Tabela 5). Esses resultados reforçam a capacidade de as plantas de milheto promoverem a biodescompactação do solo, já que apresentam um sistema radicular de crescimento rápido e elevado aporte de raízes, sendo capaz de romper camadas compactadas e de proporcionar a formação de bioporos no solo, que promovem o aumento da porosidade do solo e, consequentemente, a redução da Ds e RP (Assis et al., 2014; Guimarães et al., 2013). 
Tabela 4 - Médias de pH em $\mathrm{CaCl}_{2}$, teores de $\mathrm{Al}^{3+}$ e $(\mathrm{H}+\mathrm{Al})$, saturação por base $(\mathrm{V})$ e por alumínio $(\mathrm{m} \%)$, de um LATOSSOLO VERMELHO distrófico, sob diferentes materiais de milheto e vegetação espontânea. $\mathrm{pH}$ values in $\mathrm{CaCl} 2$, contents of $\mathrm{Al} 3+$ and $(H+A l)$, saturation by base $(\mathrm{V})$ and aluminum $(\mathrm{m} \%)$ of a dystrophic Red Latosol under diferente materials of millet and spontaneous vegetation.

\begin{tabular}{|c|c|c|c|c|c|c|}
\hline \multirow[b]{2}{*}{$\begin{array}{l}\text { Profundidade } \\
\qquad(\mathrm{m})\end{array}$} & \multicolumn{5}{|c|}{ Tratamentos } & \multirow[b]{2}{*}{ CV (\%) } \\
\hline & ADR500 & ADR300 & ADR7020 & ADR8010 & $\begin{array}{l}\text { Vegetação } \\
\text { Espontânea }\end{array}$ & \\
\hline $\begin{array}{l}0-0,20 \\
0,20-0,40\end{array}$ & $\begin{array}{l}5,33 \mathrm{a} \\
5,31 \mathrm{a}\end{array}$ & $\begin{array}{l}5,34 \mathrm{a} \\
5,30 \mathrm{a}\end{array}$ & $\begin{array}{c}-\mathrm{pH} \mathrm{CaCl} \\
5,35 \mathrm{a} \\
5,34 \mathrm{a}\end{array}$ & $\begin{array}{l}5,38 \mathrm{a} \\
5,34 \mathrm{a}\end{array}$ & $\begin{array}{l}5,25 \mathrm{a} \\
5,29 \mathrm{a}\end{array}$ & $\begin{array}{l}2,4 \\
3,9\end{array}$ \\
\hline $\begin{array}{l}0-0,20 \\
0,20-0,40\end{array}$ & $\begin{array}{l}0,13 \mathrm{a} \\
0,13 \mathrm{a}\end{array}$ & $\begin{array}{l}0,13 \mathrm{a} \\
0,09 \mathrm{a}\end{array}$ & $\begin{array}{c}{ }^{3+},\left(\mathrm{cmol}_{\mathrm{c}} \mathrm{dr}\right. \\
0,08 \mathrm{~b} \\
0,06 \mathrm{a}\end{array}$ & $\begin{array}{l}0,09 a b \\
0,09 a\end{array}$ & $\begin{array}{l}0,11 \mathrm{ab} \\
0,08 \mathrm{a}\end{array}$ & $\begin{array}{l}21,4 \\
37,1\end{array}$ \\
\hline $\begin{array}{l}0-0,20 \\
0,20-0,40\end{array}$ & $\begin{array}{l}4,98 \mathrm{a} \\
4,93 \mathrm{a} \\
\end{array}$ & $\begin{array}{l}5,15 a \\
5,00 a\end{array}$ & $\begin{array}{c}\text { + Al, }\left(\mathrm{cmol}_{\mathrm{c}}\right. \\
4,85 \mathrm{a} \\
4,70 \mathrm{a} \\
\end{array}$ & $\begin{array}{c}5,00 \mathrm{a} \\
4,53 \mathrm{a}\end{array}$ & $\begin{array}{l}4,68 \mathrm{a} \\
4,55 \mathrm{a} \\
\end{array}$ & $\begin{array}{r}6,3 \\
13,8 \\
\end{array}$ \\
\hline $\begin{array}{l}0-0,20 \\
0,20-0,40\end{array}$ & $\begin{array}{l}7,52 \mathrm{ab} \\
6,96 \mathrm{a}\end{array}$ & $\begin{array}{l}7,78 \mathrm{ab} \\
7,16 \mathrm{a}\end{array}$ & $\begin{array}{c}\mathrm{C},\left(\mathrm{cmol}_{\mathrm{c}} \mathrm{d}\right. \\
7,19 \mathrm{~b} \\
6,98 \mathrm{a}\end{array}$ & $\begin{array}{l}7,88 \mathrm{a} \\
6,80 \mathrm{a}\end{array}$ & $\begin{array}{l}7,48 \mathrm{ab} \\
6,74 \mathrm{a}\end{array}$ & $\begin{array}{r}3,5 \\
10,2 \\
\end{array}$ \\
\hline $\begin{array}{l}0-0,20 \\
0,20-0,40\end{array}$ & $\begin{array}{l}34,17 \mathrm{a} \\
29,60 \mathrm{a}\end{array}$ & $\begin{array}{l}34,14 \mathrm{a} \\
30,36 \mathrm{a} \\
\end{array}$ & $\begin{array}{l}-\mathrm{V},(\%) \\
33,10 \mathrm{a} \\
32,53 \mathrm{a}\end{array}$ & $\begin{array}{l}36,68 \mathrm{a} \\
33,91 \mathrm{a}\end{array}$ & $\begin{array}{l}37,89 \text { a } \\
33,19 \text { a }\end{array}$ & $\begin{array}{r}7,3 \\
11,8 \\
\end{array}$ \\
\hline $\begin{array}{l}0-0,20 \\
0,20-0,40\end{array}$ & $\begin{array}{l}5,02 a \\
5,88 a\end{array}$ & $\begin{array}{l}4,72 \mathrm{a} \\
4,10 \mathrm{a}\end{array}$ & $\begin{array}{l}\text { m, (\%) } \\
2,92 \mathrm{a} \\
2,65 \mathrm{a}\end{array}$ & $\begin{array}{l}2,99 \mathrm{a} \\
3,68 \mathrm{a}\end{array}$ & $\begin{array}{l}3,93 \mathrm{a} \\
3,52 \mathrm{a}\end{array}$ & $\begin{array}{l}26,1 \\
38,4\end{array}$ \\
\hline
\end{tabular}

Médias seguidas de mesma letra minúscula na linha não diferem entre si, pelo teste de Tukey, a $5 \%$ de probabilidade. Averages followed by the same lowercase letter in the line do not differ from each other, based on the Tukey test, at 5\% probability.

Tabela 5 - Valores médios da densidade do solo (Ds), da porosidade total $(\mathrm{Pt})$ e da resistência do solo à penetração de raízes (RP), de um LATOSSOLO VERMELHO distrófico, sob diferentes materiais de milheto e vegetação espontânea, em duas profundidades. Average values of soil density (Ds), total porosity (Pt) and soil resistance to root penetration (PR) of a dystrophic Red Latosol under different millet materials and spontaneous vegetation at two depths.

\begin{tabular}{lccc}
\hline Tratamentos & $\begin{array}{c}\mathrm{Ds} \\
\left(\mathrm{kg} \mathrm{dm}^{-3}\right)\end{array}$ & $\begin{array}{c}\mathrm{Pt} \\
(\%)\end{array}$ & $\begin{array}{c}\mathrm{RP} \\
(\mathrm{MPa})\end{array}$ \\
\hline ADR500 & $1,38 \mathrm{~b}$ & $48,95 \mathrm{a}$ & $2,11 \mathrm{~b}$ \\
ADR300 & $1,40 \mathrm{~b}$ & $48,17 \mathrm{a}$ & $2,45 \mathrm{~b}$ \\
ADR7020 & $1,41 \mathrm{~b}$ & $48,10 \mathrm{a}$ & $2,04 \mathrm{~b}$ \\
ADR8010 & $1,39 \mathrm{~b}$ & $49,18 \mathrm{a}$ & $2,25 \mathrm{~b}$ \\
Vegetação Espontânea & $1,49 \mathrm{a}$ & $44,69 \mathrm{~b}$ & $3,10 \mathrm{a}$ \\
\hline Profundidade (m) & - & - & - \\
\hline $0-0,10$ & $1,39 \mathrm{~b}$ & $49,64 \mathrm{a}$ & $2,19 \mathrm{~b}$ \\
$0,10-0,20$ & $1,43 \mathrm{a}$ & $46,96 \mathrm{~b}$ & $2,59 \mathrm{a}$ \\
\hline CV $(\%)$ & 2,70 & 3,10 & 14,31 \\
\hline
\end{tabular}

Médias seguidas de mesma letra minúscula na coluna não diferem entre si, pelo teste de Tukey, a $5 \%$ de probabilidade. Averages followed by the same lowercase letter in the column do not differ from each other, based on the Tukey test, at 5\% probability.

Esses resultados indicam que o cultivo de milheto pode proporcionar efeitos benéficos aos atributos físicos do solo e favorecer o desenvolvimento das culturas sucessoras como a soja. Estudos conduzidos por Gonçalves et al. (2006) constataram a capacidade de 0 milheto ADR500 crescer em camadas compactadas, promovendo com isso a descompactação do solo e a melhoria do ambiente cultivado para o desenvolvimento das próximas culturas.

Avaliando os níveis de RP e Ds na área sob vegetação espontânea, pode-se observar que os mesmos estão acima dos níveis críticos estabelecidos pela literatura, os quais variam de 2,5 a 3,0 MPa para RP (Beutler \& Centurion, 2003) e $1,45 \mathrm{~kg} \mathrm{dm}^{-3}$ para Ds (Reinert et al., 2008). Valores acima desses níveis limitam o crescimento radicular da maioria das culturas e consequentemente reduzindo a produtividade. Com isso, quando se mantém uma área com baixa ocorrência de vegetação espontânea, portanto com baixa cobertura vegetal, aliado ao fato da sua permanência 
sob escassez hídrica, não são proporcionadas condições para que o crescimento radicular seja suficiente para a formação de bioporos com efeito de descompactação do solo e de redução da RP e Ds.

Analisando as camadas do solo, pode-se observar maior nível de compactação na profundidade de 0,10-0,20 m, em relação àquela de 0-0,10 m (Tabela 5). Isso é, possivelmente, devido à maior pressão exercida pelo tráfego de máquinas agrícolas, na profundidade de $0,10-0,20 \mathrm{~m}$, em relação à de 0 0,10 m no SSD, acarretando aumento da Ds e RP e redução da Pt (Torres et al., 2015). Além disso, pôde observar-se baixo índice de precipitação pluviométrica ocorrido durante a condução do experimento (Figura 1), e também o teor de fósforo no solo estar em níveis muito baixos (Sousa \& Lobato, 2004), causando limitação no crescimento do sistema radicular do milheto; com isso, não havendo aporte suficiente de volume radicular para promover a descompactação do solo, na camada de 0,10-0,20 m (Tabela 5).

Os valores de produtividade de grãos de soja variaram entre 1.792 e $1.906 \mathrm{~kg} \mathrm{ha}^{-1}$ (Tabela 6), os quais são considerados baixos, de acordo com a média nacional de $2.865 \mathrm{~kg} \mathrm{ha}^{-1}$, na safra de 2013/2014 (CONAB, 2014). Essa baixa produtividade de grãos de soja, provavelmente, foi devido ao reduzido índice de precipitação ocorrido na área experimental. Isso foi observado principalmente no mês de janeiro, o que coincidiu com o período entre a floração e o enchimento de grãos, estádios em que a cultura da soja necessita de maior quantidade de água disponível para as plantas. A cultura da soja atinge sua máxima exigência de água nessa fase, e a redução hídrica pode provocar distúrbios fisiológicos nessa cultura, com a consequente redução em sua produtividade (Gava, 2014).

Tabela 6 - Valores médios de produtividade e massa de 100 grãos de soja, em um LATOSSOLO VERMELHO distrófico, sob diferentes materiais de milheto e vegetação espontânea. Average yield and dry mass values of 100 grains of soybean in a dystrophic Red Latosol under different materials of millet and spontaneous vegetation.

\begin{tabular}{|c|c|c|c|c|c|}
\hline \multicolumn{5}{|c|}{ Tratamentos } & \multirow[b]{2}{*}{ CV (\%) } \\
\hline ADR500 & ADR300 & ADR7020 & ADR8010 & $\begin{array}{l}\text { Vegetação } \\
\text { Espontânea }\end{array}$ & \\
\hline \multicolumn{6}{|c|}{ - } \\
\hline 1906 a & $1.784 \mathrm{a}$ & 1.785 a & $1.851 \mathrm{a}$ & $1.792 \mathrm{a}$ & 10,33 \\
\hline $9,57 \mathrm{a}$ & $9,37 \mathrm{a}$ & $9,71 \mathrm{a}$ & $9,52 \mathrm{a}$ & $9,55 \mathrm{a}$ & 4,95 \\
\hline
\end{tabular}

Médias seguidas de mesma letra minúscula na linha não diferem entre si, pelo teste de Tukey, a 5\% de probabilidade. Averages followed by the same lowercase letter in the line do not differ from each other, based on the Tukey test, at $5 \%$ probability.

Não houve diferença entre os tratamentos para a produtividade e a massa seca de 100 grãos da soja (Tabela 6). Isso também deve ter ocorrido devido ao estresse hídrico, o que uniformizou os tratamentos para essas avaliações. Assim, mesmo com as melhorias dos atributos químicos e físicos do solo, proporcionadas pelas coberturas com milheto, isso não foi suficiente para reduzir os impactos do estresse hídrico, que também ocorreram na cultura da soja em cultivo subsequente.

A utilização dos milhetos, como plantas de cobertura do solo na entressafra, mostrou-se viável mesmo com sua semeadura em épocas tardias. Isso ocorreu devido aos benefícios verificados pelos mesmos, que variaram conforme quais deles foram utilizados. Seu cultivo ocasionou melhorias em alguns dos atributos físicos e químicos do solo e aumento no acúmulo de macronutrientes na biomassa seca da parte área dos mesmos. Além disso, observou-se maior produtividade de alguns desses milhetos testados. Apesar dessas melhorias proporcionadas por seu cultivo, devido principalmente ao estresse hídrico, isso não se refletiu nos rendimentos da soja, como cultura sucessora.

Novos estudos precisam ser feitos com esses milhetos (ADR300, ADR500, ADR7020 e ADR8010), como, por exemplo, sua semeadura por várias entressafras para verificar seus efeitos a longo prazo, avaliando assim seus possíveis benefícios no solo e na produtividade da cultura sucessora, como a soja.

\section{Conclusões}

Os milhetos ADR500 e o ADR8010 apresentaram maior produção de biomassa seca da parte aérea e acúmulo de $\mathrm{N}$, em relação ao ADR300 e ADR7020, e maior acúmulo de $\mathrm{K}$, em relação ao AD300.

As áreas sob cultivo com os milhetos apresentaram maior teor de $\mathrm{K}$ no solo, na camada de 0 a $0,20 \mathrm{~m}$ de profundidade, do que sob vegetação espontânea.

A utilização dos milhetos proporcionou a redução da resistência do solo à penetração de raízes, densidade do solo e elevação da porosidade total, em relação à área sob vegetação espontânea.

A utilização do ADR300, ADR500, ADR7020 e ADR8010, como planta de cobertura do solo na entressafra, não ocasionou alterações nos rendimentos da soja, como cultura sucessora. 


\section{Agradecimentos}

À Fundação de Amparo à Pesquisa de Estudo de Goiás (FAPEG), pelo auxílio financeiro e concessão da bolsa de estudo.

\section{Referências}

Alvarenga RC, Lara Cabezas WA, Cruz JC, Santana DP (2001) Plantas de cobertura do solo para sistema plantio direto. Informe Agropecuário 22(208): 25-36.

Assis RL, Abreu H A, Pires FR, Braz JBP, Silva AG (2014) Crescimento do Jatrophacurcas L. sob diferentes níveis de compactação do solo. Enciclopédia Biosfera 10(19): 636- 646.

Beutler NA, Centurion JF (2003) Efeito do conteúdo de água e da compactação do solo na produção de soja. Pesquisa Agropecuária Brasileira 38(7): 849-856.

Boer CA, Assis RL, Silva GP, Braz AJBP, Barroso ALL, Cargnelutti Filho A, Pires FR (2007) Ciclagem de nutrientes por plantas de cobertura na entressafra em um solo de cerrado. Pesquisa Agropecuária Brasileira, Brasília 42(9):1269-1276.

Boer CR (2006) Dinâmica da decomposição e ciclagem de nutrientes de plantas de cobertura em safrinha. Universidade de Rio Verde (Dissertação de mestrado em Produção Vegetal).

Burle ML, Carvalho A M, Amabile RF, Pereira J(2006) Caracterização das espécies de adubo verde. In: Carvalho AM, Amabile, R. F. (Ed) Cerrado - adubação verde. Planaltina: Embrapa Cerrados. Cap. 3. p.71142.

Cardoso DP, Silva MLN, Carvalho GJ, Freitas DAF, Avanzi JC (2013) Espécies de plantas de cobertura no recondicionamento químico e físico do solo. Agrária Revista Brasileira de Ciências Agrárias 8(3): 375-382.

Carvalho AM, Amabile RF (2006) Cerrado: adubação verde. Embrapa Cerrados. $369 \mathrm{p}$.

Carvalho MAC, Soratto RP, Alves MC, Arf O, De Sá ME (2007) Plantas de cobertura, sucessão de culturas e manejo do solo em feijoeiro. Bragantia 66(4): 659668.

Carvalho WP, Carvalho GJ, Abbade Neto DO, Teixeira LGV (2013) Desempenho agronômico de plantas de cobertura usadas na proteção do solo no período de pousio. Pesquisa Agropecuária Brasileira 48(2):157166.

CONAB (2014) Acompanhamento da safra brasileira de grãos2013/2014 - 12ํlevantamento da produção de grãos da safra/setembro de 2014. Disponível em: <http: //www.conab.gov.br>(Acesso em: 06 jul. 2016).
CONAB (2015) Acompanhamento da safra brasileira de grãos 2014/2015 - 12ำ levantamento da produção de grãos da safra/setembro de 2015. Disponível em: <http: //www.conab.gov.br> (Acesso em: 06 jul 2016).

Embrapa - Empresa Brasileira de Pesquisa Agropecuária (2011) Tecnologias de produção de soja - região Central do Brasil 2012 e 2013. Londrina, 264p.

Embrapa - Empresa Brasileira de Pesquisa Agropecuária (1997) Manual de métodos de análise de solo. 2.ed. Rio de Janeiro, 212p.

Embrapa - Empresa Brasileira de Pesquisa Agropecuária (1999) Manual de análises químicas de solos, plantas e fertilizantes. 1.ed. Brasília, 370p.

Embrapa - Empresa Brasileira de Pesquisa Agropecuária (2006) Sistema brasileiro de classificação de solos. 2 ed. Rio de Janeiro, 306p.

Gava R (2014) Os efeitos do estresse hídrico na cultura da soja (Glycinemax, (L.) Merrill.). Escola Superior de Agricultura "Luiz de Queiroz" (Tese de doutorado em Agronomia). Disponível em:< http://www.teses.usp.br/teses/disponiveis/11/11143/tde -15092014-113209/pt-br.php> (Acesso em: 28 set. 2015).

Gonçalves WG, Jimenez RL, Araújo Filho JV, Assis RL, Silva GP, Pires FR (2006) Sistema radicular de plantas de cobertura sob compactação do solo. Engenharia Agrícola26(1): 67-75.

Guimarães CV, Assis RL, Simon GA, Pires FR, Ferreira RL, Santos DC (2013) Desempenho de cultivares e híbridos de milheto em solo submetido a compactação. Revista Brasileira de Engenharia Agrícola e Ambiental17(11):1188-1194.

Malavolta E, Vitti GC, Oliveira SA (1997) Avaliação do estado nutricional das plantas - princípios e aplicações. Potafos. 319p.

Marcante NC, Camacho MA, Paredes FPJ (2011) Teores de nutriente no milheto como cobertura de solo. BioscienceJournal 27(2): 196-204.

Menezes LAS, Leandro WM, Oliveira Junior JP, Ferreira ACB, Santana JG, Barros RG (2009) Produção de fitomassa de diferentes espécies, isoladas e consorciadas, com potencial de utilização para cobertura do solo. BioscienceJournal25(1): 7-12.

Meurer EJ (2006) Potássio. In: Fernandes MS (ed) Nutrição mineral de plantas. SBCS. p. 281-298.

Penteado SR (2010) Adubos verdes e produção de biomassa - melhoria e recuperação dos solos. Via Orgânica.168 p. 
Pereira Filho IA, Coelho AM, Karam D, Rodrigues JAS, Cruz JC (2003) Manejo da cultura do milheto. Embrapa Milho e Sorgo - CNPMS. 17p. (Circular técnica, 29).

Pires FR, Assis RL, Silva GP, Braz AJBP, Santos SC, Viera Neto AS, Souza PG (2007) Desempenho agronômico de variedades de milheto em razão da fenologia em pré-safra. Bioscience Journal 23(3): 41-49.

Reinert DJ, Albuquerque JÁ, Reichert JM, Aita C, Andrada MMC (2008) Limites críticos de densidade do solo para o crescimento de raízes de plantas de cobertura em argissolo vermelho. Revista Brasileira de Ciência do Solo32:1805-1816.

Sousa DMG, Lobato E (2004) Cerrado - correção do solo e adubação. Embrapa Informações Tecnológicas. $416 p$.

Stolf R (1991) Teoria e teste experimental de fórmulas de transformação dos dados de penetrômetro de impacto em resistência do solo. Revista Brasileira de Ciência do Solo15: 229-235.

Teixeira CM, Carvalho GJ, Furtini Neto AE, Andrade MJB, Marques ELS (2005) Produção de biomassa e teor de macronutrientes do milheto, feijão-de-porco e guandu-anão em cultivo solteiro e consorciado. Revista Ciência Agrotecnologia 29(1): 93 - 99.
Teixeira CM, Carvalho GJ, Silva CA, Andrade MJB, Pereira JM (2010) Liberação de macronutrientes das palhadas de milheto solteiro e consorciado com feijão de - porco sob cultivo de feijão. Revista Brasileira de Ciência do Solo 34: 497-505.

Torres JLR, Pereira MG, Adrioli I, Polidoro JC, Fabian AJ (2005) Decomposição e liberação de nitrogênio de resíduos culturais de plantas de cobertura em um solo de Cerrado. Revista Brasileira Ciência do Solo 29: 609-618.

Torres JLR, Pereira MG, Fabian AJ (2008) Produção de fitomassa por plantas de cobertura e mineralização de seus resíduos em plantio direto. Pesquisa Agropecuária Brasileira 43(3): 421-428.

Torres JLR, Silva MG, Souza Cunha MA, Valle DXP, Pereira MG (2014) Produção de fitomassa e decomposição de resíduos culturais de plantas de cobertura no cultivo da soja em sucessão. Revista Caatinga 27(3) 247-253.

Torres JLR, Souza ZM, Pereira MG, Assis RL (2015) Atributos indicadores da qualidade do solo numa área sob plantio direto há doze anos. Comunicata Scientiae 6(2)123-133. 